\title{
ПЕДАГОГИЧЕСКИЕ ТЕХНОЛОГИИ
}

\section{СИСТЕМНО-СТРУКТУРНЫЙ ПОДХОД В ФОРМИРОВАНИИ ПОНЯТИЙНОГО МЫШЛЕНИЯ ОБУЧАЮЩИХСЯ НА УРОВНЕ СРЕДНЕГО ОБЩЕГО ОБРАЗОВАНИЯ}

\author{
М. В. Глебова
}

\begin{abstract}
Аннотация. Однил из иелевьх ориентиров Федерального государственного образовательного стандарта среднего общего образования выступает подготовка креативных и критически мыслящих выпускников школь, владеющих основали научных методов познания окружающего мира, мотивированных на творчество и инноваиионную деятельность. Ведущей составляющей творчества является интеллект, позволяюший с высокой эбббективностью решать улственные задачи, в тол числе при ограниченнол объеме информации. Поэтолу особую значилость в современной общеобразовательной школе приобретает проблела интеллектуального развития обучающихся, которая непосредственно связана с фборлированиел их понятийного мыюшления. С позиций систелно-структурного подхода фборлирование понятийного мышления осушествляется в школьном возрасте в ходе освоения учебных дисииплин, построенных по понятийнолу принципу, на основе метода научного познания и способов действий, присущих конкретному предлету. Понятийное мьшление в ралках данного подхода рассматривается как систелное качество, обладающее свойствали многолерности, многоуровневости и диналичности, которое включает личностные и когнитивные конструкты. Согласно приниипу структурности, понятийное мышление выступает как психическая фбункиия, которая не только сала структурирована, но и включается в структуру личности. На основе теоретических и элпирических данных расслатривается диалектическая взаилосвязь логической и психологической сторон мышления, показано, что рост репродуктивной (логической) составляющей мышления оказывает существенное положительное влияние на развитие творческого мышления обучающихся. Такюе автор выделяет словесно-логический метод обучения в качестве систелообразующего колпонента учебного процесса, устанавливающего взаилосвязи между всеми колпонентали педагогической систелы, направленной на развитие понятийного мышления обучающихся. С позиций систелно-структурного подхода характеризуются особенности развития понятийного мышления обучающихся 10-11-го классов общеобразователь-
\end{abstract}

(ㄷ) Глебова М. В., 2020

Контент доступен по лицензии Creative Commons Attribution 4.0 International License

The content is licensed under a Creative Commons Attribution 4.0 International License 
ной школь: структурирование содержания образования на основе приниипа научной подачи инборлаиии, ориентация познавательной деятельности обучающихся в направлении овладениел методами и законами научного познания, фборлирование логических качеств мышления посредством словесно-логического метода обучения, углубленная предметная и логическая подготовка педагогических кадров.

Ключевые слова: федеральный государственный образовательный стандарт, творческая деятельность, понятийное мышление, систелно-структурный подход, словесно-логический метод обучения, интеллект, школьное образование.

\section{A SYSTEM-STRUCTURAL APPROACH TO THE FORMATION OF CONCEPTUAL THINKING OF STUDENTS AT THE LEVEL OF SECONDARY GENERAL EDUCATION}

\section{V. Glebova}

Abstract. One of the targets of the Federal state educational standard of General secondary education is the training of creative and critical thinking of high school graduates who know the basics of scientific methods of cognition of the world, motivated for creativity and innovation. The leading component of creativity is intelligence, allowing with high efficiency to solve mental tasks, including a limited amount of information. Therefore, the problem of intellectual development of students, which is directly related to the formation of their conceptual thinking, acquires a special significance in modern general education school. From the standpoint of system-structural approach the formation of conceptual thinking is at school age in the development of academic disciplines, built on the conceptual principle of the scientific method and ways of the actions inherent in the particular subject. Conceptual thinking in this approach is viewed as a systemic quality that has the properties of multidimensionality, multilevelity and dynamism, which includes personal and cognitive constructs. According to the principle of structure, conceptual thinking is a mental function, which is not only structured, but also included in structure of the personality. On the basis of theoretical and empirical data, the dialectical interrelation of the logical and psychological aspects of thinking is considered. It is shown that the growth of the reproductive (logical) component of thinking has a significant positive impact on the development of creative thinking of students. Also the author identifies verbal-logical method of learning as strategic component of the educational process that establishes the relationship between all components of the pedagogical system aimed at developing conceptual thinking of students. From the standpoint of the system-structural approach the peculiarities of development of conceptual thinking of students of 10-11 grades of secondary school are characterized: structuring of the content of education based on the principle of scientific presentation of information, orientation of cognitive activity of students in the direction of mastering the methods and laws of scientific knowledge, the formation of logical qualities of thinking through the verbal and logical method of teaching, in-depth subject and logical training of teaching staff.

Keywords: federal state educational standard, creative activity, conceptual thinking, a system-structural approach, the verbal-logical method of teaching, intellect, school education. 
$\Phi$ едеральный государственный стандарт среднего общего образования (далее - ФГОС СОО) ориентирует общеобразовательную школу на создание условий для интеллектуального развития обучающихся, становление таких личностных характеристик выпускника, как мотивация на творческую деятельность, осознание ценности образования, науки, творчества, овладение основами научных методов познания окружающего мира, готовность осуществлять учебно-исследовательскую, проектную и информационнопознавательную деятельность [1].

Понятийное мышление является ведущим качеством не только когнитивного, но и целостного личностного развития. Школьный возраст - сензитивный период для формирования понятийного мышления, которое не является врожденным, а приобретается в ходе систематического изучения наук, построенных по понятийному принципу. В период школьного обучения данный вид мышления развивается постепенно, на основе практического и наглядночувственного опыта обучающихся.

Проблемы понятийного мышления представляют научный интерес для педагогической теории и практики, так как «мышление в понятияХ» обладает широким набором инструментов для решения интеллектуальных задач любой степени сложности и опосредует успешность творческой деятельности.

В системе современного образования сложились противоречия, с одной стороны, между постоянно возрастающим объемом знаний и ограниченным временем обучения, с другой стороны, между ориентацией школы на подготовку креативных выпускников школы, мотивированных на творчество, инновационную деятельность, и репродуктивными методами обучения, сдерживающими интеллектуальное развитие обучающихся. Данные противоречия выступают в качестве факторов, сдерживающих развитие понятийного мышления школьников как важнейшей составляющей творческой деятельности и базы для личностного и профессионального роста.
По нашему мнению, разрешение данных противоречий возможно с методологических позиций системно-структурного подхода, который дает целостное представление о свойствах сложных объектов, рассматривает все структурные компоненты во взаимосвязи и характеризует процесс понятийного мышления с двух сторон: как системное качество и как психическую функцию, включенную в структуры личности. Развитие творческого мышления неразрывно связано с развитием его репродуктивной (логической) составляющей, которая оказывает стимулирующее влияние на развитие продуктивного (творческого) мышления. Формирование творческого мышления у обучающихся 10-11-х классов общеобразовательной школы, на наш взгляд, должно идти через развитие системы регулирующих механизмов продуктивной умственной деятельности на основе когнитивно-личностных конструктов понятийного мышления [2].

На современном этапе в ситуации возросших требований к использованию интеллектуальных ресурсов и способностей творческой личности к постановке и решению сложных интеллектуальных задач, в целях реализации целевых установок ФГОС СОО необходимо актуализировать вопросы формирования понятийного мышления обучающихся в общеобразовательной школе.

Современной педагогической психологией всесторонне исследован и обоснован факт определяющего влияния обучения на процесс психического развития субъекта, в ходе которого существенные содержательные и динамические изменения претерпевает активная творческая функция: мышление. В период школьного обучения, сензитивного для развития мышления, закладываются основы продуктивной умственной деятельности, формируется система научных понятий, которая становится базой для дальнейшего развития личности.

За рамками школьного возраста, как показывает практика, корректирующие воздействия на познавательную сферу личности оказываются менее продуктивными. 
Теорию понятийного мышления в своих работах обосновал Л. С. Выготский и в обобщенном виде выделил три ключевые характеристики этого вида мышления: умение выделять суть явления, объекта; умение видеть причину и прогнозировать последствия; умение систематизировать информацию и строить целостную картину ситуации [3]. В. М. Розин отмечает, что теория Л. С. Выготского движется в пространстве двоякого понимания мышления. С одной стороны, используется семантический подход к определению мышления: мышление есть выработка и оперирование обобщенными значениями, образующими содержание понятий. С другой стороны, мышление определяется как сознательная мыслительная деятельность: мышление есть решение задач, логическое использование понятий [4, с. 46-47].

Методологические основы системного развития мышления, базирующиеся на диалектическом подходе, развивали М. М. Бахтин, Э. В. Ильенков, Б. М. Кедров, И. В. Николаев, Г. П. Федотов и др. В трудах философов и логиков Е. К. Войшвилло, А. Д. Гетмановой, Д. П. Горского, Е. А. Иванова, Б. М. Кедрова, Н. И. Кондакова и др. исследовались логические функции и структура понятий, выявлялись взаимосвязи форм мышления. Психологические механизмы образования понятий изучали П. П. Блонский, Л. С. Выготский, А. Н. Леонтьев, Н. А. Менчинская, С. Л. Рубинштейн, А. А. Смирнов, М. А. Холодная. Проблемы формирования понятий и развития понятийного мышления в школьном возрасте отражены в работах психологов и дидактов Г. А. Буткина, И. А. Володарской, Л. С. Выготского, П. Я. Гальперина, В. А. Гусева, Э. Г. Гельфман, В. В. Давыдова, В. А. Далингера, Г. И. Железовской, Л. В. Занкова, Е. Н. Кабановой-Миллер, Н. А. Менчинской, Н. Ф. Талызиной, А. В. Усовой, М. Н. Шардакова, Л. И. Ясюковой и др.

В теории познания «понятие» рассматривается как форма мыслительного отражения, обеспечивающая обобщенное познание объектов и явлений окружающего мира в единстве их существенных призна- ков и отношений; оно определяется через его подчинение родовому понятию и через его специфическое отличие от других соподчиненных тому же самому родовому понятию терминов. Потому не существует единичных понятий, они всегда образуют систему, которой представлена та или иная научная область. Формирование понятий происходит в процессе познания людьми объективных законов природы и общества, научно-исследовательской деятельности человечества [5, с. 87-101].

Л. А. Ясюкова отмечает, что в психологических исследованиях механизм образования понятий часто связывают с логической операцией классификации или с выделением характерных признаков [6]. Само понятие представляется как кумулятивный (интегральный) итог разнообразной и разноуровневой деятельности индивидов [7], «совокупность определенных существенных признаков и правил, связывающих эти признаки» [8]. Аналогичных взглядов придерживаются отечественные ученые, разрабатывающие проблемы развития мышления детей (Ю. В. Бабаева, Д. Б. Богоявленская, В. Н. Дружинин, А. И. Савенков и др.) [9; 10].

Согласно логико-философским позициям, акцентирующим внимание на структурно-функциональных характеристиках объекта, можно определить понятийное мышление как процесс активного отражения окружающей действительности посредством выявления и вербальной фиксации в операционных единицах - понятиях и их системах - существенных характеристик объектов и отношений общности, причинно-следственных зависимостей между ними, с одновременным осознанием субъектом этих отношений и зависимостей, что выражается вовне раскрытием закономерностей явлений, переходом знаний от менее глубокой сущности к сущности более глубокой через разрешение диалектических противоречий; характеризуется как итог познавательной деятельности.

Понятийное мышление, как отмечал Л. С. Выготский, возникает на этапе, когда субъект начинает осознанно применять 
мыслительные операции абстрагирования, сравнения, анализа и синтеза, в понятийном значении фиксируются существенные общие признаки класса предметов, а его образование подчиняется логическим отношениям общего и единичного [11, с. 181]. Развитие понятийного мышления происходит через разрешение диалектических противоречий: путем преодоления гносеологических «барьеров», связывания между собой явлений, событий, отдельных фактов, объектов, групп предметов посредством их систематизации на основе выделения существенных признаков, установления иерархических родо-видовых и объективноследственных зависимостей.

В психологическом плане усвоение систематизированных научных знаний формирует не только внешние упорядоченные и взаимосвязанные системы понятий, но и внутреннюю когнитивную структуру, в рамках которой облегчается перенос навыков, приемов деятельности, усвоенных закономерностей. Таким образом, понятийное мышление является основной психологической характеристикой, абсолютно необходимой для организованного, в частности, школьного обучения.

Целевые установки ФГОС СОО ориентируют на создание условий для подготовки креативных и критически мыслящих обучающихся, активно и целенаправленно познающих мир, осознающих ценность образования и науки, труда и творчества для человека и общества; владеющих основами научных методов познания окружающего мира.

Содержание образования является одной из важнейших составляющих целостного педагогического процесса, направленного на развитие творческого потенциала личности и понятийного мышления как основы для его реализации.

Результаты освоения содержания учебных предметов в рамках образовательных областей определяют те итоговые результаты, которые должны демонстрировать обучающиеся по завершении обучения в средней школе. Независимо от особенностей того или иного предмета вместе они образу- ют целостное содержание образования, которое априори не должно делиться на несколько независимых ветвей и циклов.

Согласно ФГОС СOO, предметные результаты освоения основной образовательной программы должны включать широкий набор познавательных компетенций обучающихся: элементы логической, методологической, общеучебной деятельности, соотнесённой с реальными познаваемыми объектами. Эти компетенции как на базовом, так и углубленном уровне опосредуются важнейшими качествами, связанными с развитием когнитивных структур личности: осмыслением понятийного аппарата наук, сформированностью умений обобщать, анализировать и оценивать информацию (теории, концепции, факты), целостностью восприятия окружающей действительности.

Как указано в разделе «Требования к результатам освоения основной общеобразовательной программы» ФГОС СОО, углубленный уровень изучения предмета отличается от базового курса, ориентированного на обеспечение преимущественно общеобразовательной и общекультурной подготовки, более глубоким освоением основ наук, систематических знаний и способов действий, присущих данному учебному предмету. Предметные результаты освоения основной образовательной программы на углубленном уровне в конечном итоге должны обеспечивать профессиональное самоопределение обучающихся и их подготовку к последующему профессиональному образованию $[1 ; 12]$.

Из примеров требований к предметным результатам освоения ООП СОО со всей очевидностью следует, что выпускник средней общеобразовательной школы для достижения целей ФГОС СОО должен обладать сформированным понятийным мышлением, которое обеспечивает существенные сдвиги в интеллектуальном развитии обучающихся и создает основу для творческой самореализации личности.

Понятийное мышление как сложный психический процесс можно охарактеризо- 
вать с позиций системного подхода, который рассматривает сложноорганизованные объекты не как совокупность элементов системы, а как тип и характер взаимосвязи элементов в структуре объекта, выявляет закономерности объединения элементов в целостную систему.

В рамках системно-структурного подхода понятийное мышление можно определить как сложную систему, состоящую из диалектически взаимосвязанных объектов (конструктов) логико-когнитивной и личностной направленности в целостной структуре психического процесса мышления. Согласно данному подходу системными качествами понятийного мышления являются: целостность, структурность, иерархичность, многоуровневость, динамичность.

В качестве когнитивных элементов понятийного мышления целесообразно выделить познавательные процессы, которые вносят важный вклад в развитие продуктивной умственной деятельности.

Логико-когнитивные конструкты понятийного мышления являются структурами для переработки и преобразования поступающей извне информации на основе выделения сущности, уровня общности и функциональных связей посредством индивидуально организованных познавательных процессов.

Личностные конструкты понятийного мышления - оценочная система, включающая конкретные идеи, мысли, которые человек использует для осмысления и истолкования, объяснения и прогнозирования своего опыта в целях классификации различных объектов его жизненного пространства.

Когнитивные и личностные составляющие понятийного мышления представляют собой систему взаимосвязанных факторов, они обеспечивают осознание субъектом существенных признаков предметов, в котором Л. С. Выготский видел специфику формирования научных понятий.

Личностные конструкты понятийного мышления обладают регулирующей функцией и, на наш взгляд, максимально про- дуктивно развиваются в русле системнодеятельностного подхода, который выступает в качестве методологической основы ФГОС COO.

Реальными носителями понятий являются конкретные научные дисциплины, в понятиях концентрируются накапливаемые научные знания [13]. Л. С. Выготский подчеркивал, что понятийное мышление формируется исключительно в процессе изучения наук и освоения научных понятий, поэтому обучение в средней школе должно опираться на базовые понятия, которые составляют фундамент различных наук. Дальнейшее развитие системы понятий предполагает категоризацию, формирование установки на поиск существенных признаков, в этом случае происходит обобщение и систематизация знаний на основе выделения существенных признаков, формируется понятийное мышление обучающихся.

В качестве системообразующего компонента учебного процесса, направленного на формирование понятийного мышления, на наш взгляд, необходимо выделить словесно-логический метод обучения. В основу данного метода обучения положены выводы и положения теории познания формальной и диалектической логики, теории продуктивного мышления о системнодинамическом характере творческой деятельности, деятельностная теория мышления, принципы дидактики.

Сущность словесно-логического метода обучения выражается в следующих характеристиках:

1. Организация учебно-познавательной деятельности на основе словесно-логического метода опирается на психологические закономерности развития мышления, которые обусловлены системно-динамическими процессами разрешения противоречий в познании. Знания обучающимся не предлагаются в «готовом виде», а добываются ими самостоятельно, затем постепенно развиваются через спиральное восхождение от абстрактного к конкретному, посредством углубления, обобщения и си- 
стематизации знаний на каждом уровне освоения учебного материала.

2. Словесно-логический метод способствует овладению методом научного познания на основе использования в учебно-познавательной деятельности общелогических методов исследования (анализ, абстрагирование, дедукция, индукция, аналогия, моделирование), гипотетико-индуктивных методов (выдвижение гипотез, вывод заключений из гипотез).

3. Развитие познавательных способностей обучающихся осуществляется через постановку сложных вопросов-суждений, как самостоятельно, так и под руководством учителя.

4. Роль словесно-логического метода обучения как компонента целостной педагогической деятельности, направленной на развитие понятийного мышления, в дидактической системе: «цели - содержание методы - формы - средства обучения» является определяющей.

5. Существенным моментом метода является воздействие учителя на все виды памяти (слуховую, образную, эмоциональную, моторную) обучающихся, которая в подростковом возрасте потенциально сильнее, чем у взрослых людей. Для формирования понятий наиболее важным является словесно-логический вид памяти, поэтому умения логического запоминания в процессе рассуждения, которые формирует словесно-логический метод обучения, значимы для усвоения разноплановых понятий.

6. В процессе овладения словесно-логическим методом обучающиеся приобретают не только умения определять существенные признаки понятия, но и оперировать ими в новых незнакомых условиях при решении познавательных задач. Применение понятия на практике является показателем степени его усвоения и одновременно средством достижения наилучшего усвоения этого понятия.

7. Особенностью словесно-логического метода является обобщение и логическая структурированность учебного материала на основе определения перечня по- нятий к соответствующему разделу предметной дисциплины, установления причинно-следственных связей между понятиями, предметами, явлениями с опорой на ранее изученный материал и межпредметные связи. Обобщение на основе выявления существенных признаков и логическая структурированность теоретического материала формируют рациональный метод умственной деятельности, что позволяет интенсифицировать процесс обучения.

8. Словесно-логический метод обучения способствует формированию логикокогнитивных конструктов понятийного мышления, которые в процессе интеллектуального развития субъекта переходят в устойчивые индивидуальные особенности психики (сосредоточенность, самостоятельность, осознанность, стремление к истине, чувствительность к противоречию и др.) и определяют в значительной степени успешность учебно-познавательной деятельности [14].

Основными формами освоения содержания учебного материала при использовании данного метода являются: лекция, самостоятельная работа учащихся и семинар. Лекционные занятия организованы в логике проблемного изложения теоретического материала, с учетом принципа историзма. Учитель на лекциях моделирует учебные ситуации, с последующей постановкой проблемных вопросов, добивается их решения в ходе занятия и самостоятельной подготовки обучающихся. На семинарских занятиях осуществляется совместная деятельность учителя и обучающихся по формированию и углублению понятий путем рассмотрения сложных вопросов-суждений, подготовленных обучающимися самостоятельно.

Мы проверили возможность применения словесно-логического метода обучения для целенаправленного формирования понятий у обучающихся 10-11-х профильных классов в рамках исследования особенностей развития понятийного мышления, в том числе при углубленном изучении химии. В учебный план эксперимен- 
тальных классов социально-гуманитарного, физико-математического и химико-биологического профилей были включены курсы логики и философии за счет школьного компонента учебного плана образовательного учреждения.

На диагностическом этапе исследования получены данные, которые свидетельствуют о недостаточной сформированности у обучающихся важнейших интеллектуальных умений классификации, обобщения и систематизации информации на основе установления существенных признаков предметов и явлений.

При анализе особенностей организации учебно-познавательного процесса в школе выявлен ряд общих существенных особенностей обучения. В частности, к числу подобных особенностей относится преимущественное стимулирование одного психического познавательного процесса памяти, которая доминирует над процессом мышления (до 90\% вопросов, задаваемых учителем на уроках, обращены к памяти обучающихся). В ходе учебных занятий применяются в подавляющем большинстве случаев вопросы, требующие перечисления существенных признаков понятий. Сложные проблемные вопросы, активизирующие мыслительную деятельность, способствующие осознанию содержания понятий, формированию умения пользоваться ими при ориентировке в предметной действительности (вопросы-суждения), используются редко и не всеми учителями.

С целью развития умений обучающихся формулировать вопросы нами была использована образовательная технология на основе словесно-логического метода обучения, которая включает в себя концептуальную основу - научную идею развития продуктивной умственной деятельности на основе когнитивно-личностных конструктов понятийного мышления, содержательный и процессуальный компоненты [2; 14].

Преобразующий эксперимент показал, что применение в 10-11-х классах средней общеобразовательной школы технологии на основе словесно-логического метода обучения способствует формированию рационального метода умственной деятельности, который включает не только целенаправленную работу учителя по формированию понятий, но и самостоятельную деятельность обучающихся по развитию своего мышления. Анализ результатов проведенного исследования свидетельствует о выявлении положительной динамики интеллектуальной активности и познавательных интересов в форме постановки сложных вопросов-суждений у обучающихся экспериментальных классов. При изучении химии на базовом и углубленном уровне в классах физико-математической, химикобиологической, гуманитарной направленности словесно-логический метод обучения позволяет школьникам полноценно усваивать научные понятия в ходе собственной познавательной деятельности, активно участвовать в процессе постановки и решения познавательных задач, что не обеспечивается обычной организацией учебного процесса. При экспериментальном обучении у испытуемых повысилась способность выделения существенных признаков понятий, целенаправленного применения понятий в процессе решения задач через включение определения понятий в действия обучающихся при разрешении проблемных ситуаций.

По данным итогового контроля преобразующего эксперимента фиксируется качественный рост логической $(34,5 \%)$ составляющей и эвристической (24,5\%) составляющих мышления обучающихся. Наибольшее приращение по фактору «индивидуальные способности личности» (44\%) находит прямое отражение в успешности обучения старшеклассников, значительного повышения их качественной успеваемости по всем предметам учебного плана. Данный факт свидетельствует о сформированности рационального метода умственной деятельности, успешно применяемого школьниками в процессе изучения различных дисциплин.

Особенностью старшего школьного возраста является активное развитие по- 
знавательного психического процесса мышления, который постепенно переходит от развернутых форм мыслительных операций к свернутым формам, то есть совершается переход от конкретно-понятийного к абстрактно-понятийному мышлению. Мыслительные задачи высокого уровня переводятся в формально-логический вид, обобщаются, решаются при глубоком и всестороннем рассмотрении их содержания путем проецирования на новые ситуации. При расширении диапазона применения мыслительных операций в незнакомых ситуациях возрастает познавательная активность обучающихся, которая проявляется в умении видеть противоречия, углубляться в содержание задачи, формулировать сложные вопросы, обосновывать собственные суждения, осознавать и контролировать мыслительные процедуры (рассуждения, умозаключения). Благодаря сформированным логическим качествам мышления процесс систематизации и углубления знаний, полученных на профильном уровне обучения, происходит более упорядоченно за счет формирования рационального метода умственной деятельности.

Рост логической составляющей мышления оказывает положительное влияние на развитие творческой (продуктивной) составляющей мышления. Такое единство репродуктивной и продуктивной составляющих творческого мышления подтверждает наличие диалектической взаимосвязи логической и психологической сторон процесса продуктивной умственной деятельности. Целенаправленное формирование логического аппарата мышления не только повышает продуктивность мыслительной деятельности, но и определяет возможные пути совершенствования процесса обучения на уровне среднего общего образования за счет развития понятийного мышления, которое является основой и интегратором интеллектуального развития школьников.

Системно-структурный подход позволяет сформулировать особенности формировании понятийного мышления обучаю- щихся на уровне среднего общего образования. Перечислим их:

1. Структурирование содержания образования на основе принципа научной подачи информации. Понятийное мышление формируется в школьном возрасте в ходе изучения научных дисциплин, построенных по понятийному принципу, в процессе освоения ведущих идей, концепций, систем знаний о законах природы, общества, а также познавательных и творческих элементов социального опыта, которые в совокупности и представляют содержание современного школьного образования.

2. Ориентация познавательной деятельности обучающихся в направлении овладением методами и законами научного познания. Овладение обучающимися методами научного познания (абстрагирование, анализ и синтез, обобщение, индукция и дедукция, моделирование и др.) происходит в процессе разрешения противоречий в познании. Знания обучающимся не предлагаются в «готовом виде», они добываются ими в процессе самостоятельной работы с элементами проблемности, при постоянной обратной связи и самоконтроле. Формирование целостного знания в рамках изучения предметных дисциплин тесно связано с философской методологией, поэтому в процессе обучения необходимо знакомить обучающихся с категориями диалектической логики, в частности, с диалектическими противоречиями как источником изменения и развития объекта, источником его «самодвижения».

3. Формирование логических качеств мышления посредством словесно-логического метода обучения. Становление и развитие понятийного мышления старшеклассников зависит от сформированности логических качеств их мышления. Методическим ориентиром для формирования понятийного мышления обучающихся является оперирование двумя группами логических операций: на основе способов обобщения существенных признаков понятий (дедуктивный, индуктивный) и видов обобщения информации (постепенное обобще- 
ние с опорой на наглядность, словесно-логическое обобщение). Это обобщение приводит к систематизации учебной информации, освоению научных знаний и последующей перестройке индивидуального опыта. Понятийное мышление как высший уровень теоретического обобщения формируется на основе уже имеющихся вербальных, предметных, образно-пространственных компонентов. Находящиеся в постоянном взаимодействии, дополняющие друг друга понятийное и образное мышление обеспечивают глубокое и разностороннее отражение действительности в разноплановых понятиях.

4. Профессиональная подготовка педагогических кадров (методологическая, предметная, методическая). Необходимыми условиями формирования понятийного мышления обучающихся являются: глубокое знание учителем содержания предмета, понятий современной науки, понимание им проблемы формирования понятий в процессе школьного обучения, наличие базовых знаний по логике и психологии мышления.

Рассмотрение вопроса об особенностях формирования понятийного мышления школьников в процессе обучения сопряжено с четким пониманием фактора возрастных и индивидуальных различий в этом процессе. Как показано в ряде психологических исследований, способность к обобщению и абстрагированию возникает еще в младшем школьном возрасте и в дальнейшем развивается в старшем школьном возрасте [6; 15]. В рамках системноструктурного подхода понятийное мышле- ние рассматривается как сложная система взаимосвязанных психологических механизмов, которые могут быть представлены совокупностью логико-когнитивных и личностных конструктов. Когнитивные и личностные составляющие понятийного мышления обеспечивают осознание информации на основе знания существенных характеристик объектов, формирование оценочных систем для объяснения и истолкования индивидуального опыта, что может оказать существенное влияние на ход и характер умственной деятельности. В старшем школьном возрасте при помощи словеснологического метода обучения активно формируются когнитивные элементы понятийного мышления, которые влияют на успешность школьного обучения, закладывают основу для дальнейшей профессиональной специализации в области естественно-математических наук, обеспечивают продуктивность умственной деятельности обучающихся.

Предлагаемый системно-структурный подход в развитии понятийного мышления согласуется с его классическим философским определением, результатами современных психолого-педагогических исследований и показывает свою педагогическую целесообразность в решении задач интеллектуального развития обучающихся, формирования важных личностных характеристик выпускника школы (мотивации на творчество и самообразование, готовности к учебно-исследовательской, информационно-познавательной деятельности), что соответствует целевым установкам ФГОС СOO.

\section{СПИСОК ЛИТЕРАТУРЫ}

1. Федеральный государственный образовательный стандарт среднего общего образования. URL: https://docs.edu.gov.ru/document/bf0ceabdc94110049a583890956abbfa/ (дата обращения: 19.11.2019).

2. Глебова М. В. Проблема интеллектуального развития школьников с позиций современной когнитивной науки // Современное педагогическое образование. 2019. № 10. С. 124-131.

3. Выготский Л. С. История развития высших психических функций. М.: Юрайт, 2019. $336 \mathrm{c}$. 
4. Мышление: сущность и развитие: концепции мышления, роль мыслящей личности, циклы развития мышления / авт.-сост. В. М. Розин. М.: ИФ PAH: URSS, 2015. 358 с.

5. Войшвилло E. K. Понятие как форма мышления: логико-гносеологический анализ. M.: URSS, 2019. 238 c.

6. Ясюкова Л. А. Проблемы психологии понятийного мышления // Вестн. С.-Петерб. ун-та. 2010. Сер. 12. Вып. 3. С. 385-394.

7. Kholodnaya M. A., Volkova E. V. Conceptual structures, conceptual abilities and productivity of cognitive functioning: the ontological approach // Procedia - Social and Behavioral Sciences. Vol. 217 (2016). P. 914-922.

8. Солсо P. [Solso R.] Когнитивная психология: пер. с англ. / 6-е изд. СПб. и др.: Питер, 2006. 589 с. (Мастера психологии).

9. Дружинин В. Н., Бабаева Ю. Д., Богоявленская Д. Б. Психология одаренности и творчества / под ред. Л. И. Ларионовой, А. И. Савенкова. М. - СПб.: Нестор-История, 2017.288 с.

10. Савенков А. И. Психодидактика. М.: Национальный книжный центр, 2012. 360 с.

11. Выготский Л. С. Мышление и речь. Психологические исследования / ред. В. М. Щербакова. М.: Национальное образование, 2019. 368 с. (Антология дошкольного образования).

12. Примерная основная образовательная программа среднего общего образования. URL: http://fgosreestr.ru/registry/primernaya-osnovnaya-obrazovatelnaya-programmasrednego-obshhego-obrazovaniya (дата обращения: 19.11.2019).

13. Выготский Л. С. Вопросы детской психологии. М.: Перспектива, 2018. 224 с.

14. Глебова M. В. Результаты экспериментального исследования особенностей развития продуктивного мышления школьников // Компетентностный подход в образовании: проблемы и пути модернизации / под общ. ред. Т. С. Фещенко. Новосибирск: Сибпринт, 2012. С. 107-143.

15. Блонский П. П. Психология и педагогика. Избранные труды. Изд. 2-е, стер. М.: Юрайт, 2019. 184 с. (Антология мысли).

\section{REFERENSES}

1. Federalnyy gosudarstvennyy obrazovatelnyy standart srednego obshchego obrazovaniya. Available at: https:/docs.edu.gov.ru/document/bf0ceabdc94110049a583890956abbfa/ (accessed: 19.11.2019).

2. Glebova M. V. Problema intellektualnogo razvitiya shkolnikov s pozitsiy sovremennoy kognitivnoy nauki. Sovremennoe pedagogicheskoe obrazovanie. 2019, No. 10, pp. 124131.

3. Vygotskiy L. S. Istoriya razvitiya vysshikh psikhicheskikh funktsiy. Moscow: Yurayt, 2019. $336 \mathrm{p}$.

4. Rozin V. M. (comp.) Myshlenie: sushchnost i razvitie: kontseptsii myshleniya, rol myslyashchey lichnosti, tsikly razvitiya myshleniya. Moscow: IF RAN: URSS, 2015. 358 p.

5. Voyshvillo E. K. Ponyatie kak forma myshleniya: logiko-gnoseologicheskiy analiz. Moscow: URSS, 2019. 238 p.

6. Yasyukova L. A. Problemy psikhologii ponyatiynogo myshleniya. Vestn. S.-Peterb. un-ta. 2010. Ser. 12, Iss. 3, pp. 385-394.

7. Kholodnaya M. A., Volkova E. V. Conceptual structures, conceptual abilities and productivity of cognitive functioning: the ontological approach. Procedia - Social and Behavioral Sciences. Vol. 217 (2016). P. 914-922.

8. Solso R. Kognitivnaya psikhologiya. St. Petersburg: Piter, 2006. 589 p. (Mastera psikhologii). (In Russian) 
9. Druzhinin V. N., Babaeva Yu. D., Bogoyavlenskaya D. B. Psikhologiya odarennosti $i$ tvorchestva. Eds. L. I. Larionovoy, A. I. Savenkova. Moscow - St. Petersburg: NestorIstoriya, 2017. $288 \mathrm{p}$.

10. Savenkov A. I. Psikhodidaktika. Moscow: Natsionalnyy knizhnyy tsentr, 2012. 360 p.

11. Vygotskiy L. S. Myshlenie i rech. Psikhologicheskie issledovaniya. Moscow: Natsionalnoe obrazovanie, 2019. 368 p. (Antologiya doshkolnogo obrazovaniya).

12. Primernaya osnovnaya obrazovatelnaya programma srednego obshchego obrazovaniya. Available at: http://gosreestr.ru/registry/primernaya-osnovnaya-obrazovatelnaya-programma-srednego-obshhego-obrazovaniya (accessed: 19.11.2019).

13. Vygotskiy L. S. Voprosy detskoy psikhologii. Moscow: Perspektiva, 2018. 224 p.

14. Glebova M. V. Rezultaty eksperimentalnogo issledovaniya osobennostey razvitiya produktivnogo myshleniya shkolnikov. In: Feshchenko T. S. (ed.) Kompetentnostnyy podkhod v obrazovanii: problemy i puti modernizatsii. Novosibirsk: Sibprint, 2012. Pp. 107143.

15. Blonskiy P. P. Psikhologiya i pedagogika. Izbrannye trudy. Moscow: Yurayt, 2019. 184 p. (Antologiya mysli).

Глебова Марина Владимировна, кандидат педагогических наук, заместитель начальника Управления образования администрации города Прокопьевска

e-mail: mvg.office@mail.ru

Glebova Marina V., PhD in Education, Deputy Head of the Education Department of the Prokopyevsk city Administration

e-mail: mvg.office@mail.ru

Статья поступила в редакцию 26.11.2019

The article was received on 26.11.2019 